\title{
Plasma fatty acids and primary open-angle glaucoma in the elderly: the Montrachet population-based study
}

\author{
Alicia Chemaly ${ }^{1}$, Louis Arnould ${ }^{1,2,3^{*}}$, Alassane Seydou ${ }^{3}$, Pierre-Henry Gabrielle ${ }^{1}$ Florian Baudin ${ }^{1,4}$, Niyazi Acar ${ }^{3}$ and \\ Catherine Creuzot-Garcher ${ }^{1,3}$
}

\begin{abstract}
Background: To compare plasma fatty acids (FAs) between participants with primary open-angle glaucoma (POAG) and participants without neuropathy in an elderly population and to investigate specific FAs pattern in POAG.

Methods: We conducted a population-based study in participants older than 75 years. Participants underwent a comprehensive eye examination with optic nerve photographs, visual field test and optic nerve OCT with RNFL thickness measurement. Glaucomatous status was defined according to the International Society for Epidemiologic and Geographical Ophthalmology classification. Lipids were extracted from plasma and FAs methylesters prepared and analyzed by gas chromatography-mass spectrometry.

Results: Among the 1153 participants of the Montrachet study 810 were retained for analysis and 68 had POAG. The mean age was $82.11 \pm 3.67$. In multivariable analysis FAs levels were not different between POAG participants and controls $(P=0.078)$. A FAs pattern characterized by high negative weight of gamma-linoleic acid, eicosapentaenoic acid polyunsaturated FAs (PUFAs), Cis-7 hexadecenoic acid monounsaturated FAs (MUFAs) and high positive weight of eicosadienoic acid, docosatetraenoic acid, docosapentaenoic n-6, alpha linoleic acid PUFAs, eicosenoic acid MUFAs, margaric acid and behenic acid saturated FAs was positively associated with POAG. After adjustment for major confounders, individuals in the upper tertile of FAs pattern scores compared with those in the lower tertile were more likely to present POAG $(\mathrm{OR}=3.09[95 \% \mathrm{Cl} 1.29-7.40] P=0.013)$.
\end{abstract}

Conclusions: We found no significant difference regarding isolated plasma FAs between participants with POAG and participants without neuropathy in elderly but specific FAs pattern might be associated with POAG.

Keywords: Elderly, Glaucoma, Population-based study, Montrachet study, Fatty acids profile

\section{Introduction}

Glaucoma is the most common optic neuropathy leading to irreversible blindness worldwide [1]. It is a progressive neuropathy with multiple risk factors characterized by the destruction of retinal ganglion cells with a corresponding

\footnotetext{
* Correspondence: louis.arnould@chu-dijon.fr

'Department of Ophthalmology, University Hospital, 14 rue Paul Gaffarel, 21079 Dijon CEDEX, France

${ }^{2}$ INSERM \& Dijon University Hospital, CIC1432, Clinical Epidemiology Unit, Dijon, France

Full list of author information is available at the end of the article
}

visual field loss. Glaucoma will affect 111.8 million people worldwide by 2040 with primary open-angle glaucoma (POAG) as the most common form [2]. Despite extensive research, its pathogenesis is still controverted. Established risk factors are age, elevated intraocular pressure (IOP), ethnic background and family history of glaucoma [3]. If elevated IOP is recognized as a major modifiable risk factor for the progression of glaucoma [4], literature shows that glaucoma can also develop under normal IOP conditions [5]. Other factors such as vascular disorder could be

C C The Author(s). 2021 Open Access This article is licensed under a Creative Commons Attribution 4.0 International License, which permits use, sharing, adaptation, distribution and reproduction in any medium or format, as long as you give appropriate credit to the original author(s) and the source, provide a link to the Creative Commons licence, and indicate if changes were made. The images or other third party material in this article are included in the article's Creative Commons licence, unless indicated otherwise in a credit line to the material. If material is not included in the article's Creative Commons licence and your intended use is not permitted by statutory regulation or exceeds the permitted use, you will need to obtain permission directly from the copyright holder. To view a copy of this licence, visit http://creativecommons.org/licenses/by/4.0/. The Creative Commons Public Domain Dedication waiver (http://creativecommons.org/publicdomain/zero/1.0/) applies to the data made available in this article, unless otherwise stated in a credit line to the data. 
involved: decreased ocular blood flow could lead to ischemia and reperfusion damage of the optic nerve [6-9]. Inflammation and oxidative stress leading to microglial and complement activation are also suspected to play a role in the pathogenesis of glaucoma [10,11].

Polyunsaturated fatty acids (PUFAs), are essential molecules of our organism. They are constituents of cell membrane, precursors of hormones such as prostaglandins and steroids and participate in the regulation of genes [12]. Linoleic acid (LA) and $\alpha$-linoleic acid (ALA) are called essentials PUFAs because they cannot be synthetized and have to be ingested in the diet. They are respectively the precursors of the omega 3 and omega 6 family of PUFAs and share the same enzymatic pathway for their production [12]. An imbalance in the input or production of these PUFAs was associated with the presence of systemic [13-15] and retinal diseases [16] such as age-related maculopathy [17], diabetic retinopathy [18]. In glaucoma, PUFAs have been suspected to play a role in the pathogenesis through their inflammatory and vascular regulation activity [19]. Previous studies investigated the link between some plasma and red blood cells membrane $(\mathrm{RBCm})$ fatty acids (FAs) and the presence of glaucoma, notably docosahexaenoic acid (DHA), ALA, and eicosapentaenoic acid (EPA) [19-21]. Results of these case-control studies converge towards a reduction of omega 3 , especially of EPA and DHA in glaucomatous participants. Similar analysis in larger population studies are necessary to confirm these results.

The purpose of our study was to compare the total plasma FAs level between participants with POAG and participants without neuropathy in an elderly population-based study and to investigate specific FAs pattern in POAG.

\section{Methods}

\section{Study design}

The Montrachet (Maculopathy Optic Nerve and nuTRition neurovAsCular and HEarT diseases) populationbased study was conducted from October 2009 to March 2013, in Dijon with volunteers, aged over 75 years. It was an ancillary study of the Three-City (3C) populationbased study. The methodology of the Montrachet and the $3 \mathrm{C}$ studies has previously been described [22, 23]. All participants gave their informed consent and the study followed the tenets of the Declaration of Helsinki. The study has been approved by the Ethical Committee and registered as 2009-A00448-49. We followed the STROBE (Strengthening the Reporting of OBsevational studies in Epidemiology) statements [24] according to the EQUATOR (Enhancing the QUAlity and Transparency Of health Research) guidelines [25].

\section{Eye examination}

Participants underwent a complete examination in the Department of Ophthalmology, in Dijon University Hospital, France. Clinical, treatment, lifestyle and demographic data as well as eating habits were collected by a self-questionnaire. The eye examination included best corrected visual acuity, slit-lamp examination, IOP measurement by air tonometry (Tonoref II, Nidek, Aichi, Japan), central corneal thickness by ultrasonic contact pachymeter (DGH 500, DGH Technology, Exton, PA, USA), axial length measurement, macular and optic disc photographs with a fundus camera (TRC NW6S, Topcon, Tokyo, Japan) after pupil dilation and a visual field for screening (Frequency-Doubling Technology, Carl Zeiss Meditec, Dublin, CA, USA). An optic nerve head spectral-domain optical coherence tomography (SDOCT) (Spectralis, Heidelberg Engineering Co., Heidelberg, Germany) was performed, after pupil dilation with retinal nerve fiber layer (RNFL) thickness measurement around a 3.5-mm-diameter circle. The diagnosis of glaucoma was determined from photographs of optical discs interpreted by two trained ophthalmologists, blinded for clinical and RNFL SD-OCT thickness data. In case of discrepancy, a glaucoma specialist adjudicated. Persons identified as glaucomatous were further examined with gonioscopy and visual field by the Swedish Humphrey Interactive Threshold Algorithm (SITA) 24-2 (Carl Zeiss Meditec, Dublin, CA, USA). Following these examinations, they were classified into three levels of evidence according to the ISGEO (International Society for Geographical and Epidemiological Ophthalmology) classification [26]. The OCT results were therefore not taken into account (Foster et al., 2002).The 97.5 and 99.5 percentiles for the vertical cup-to-disc-ratio found in our population defined the limits of the three levels of evidence at 0.7 and 0.8 respectively [27]. In this analysis, only cases of primary open-angle glaucoma were taken into account. Severity was determined with mean deviation (MD) of Humphrey's visual field according to the classification published by Hodapp et al. [28] An abnormal visual field test was defined when the Glaucoma Hemifield Test (GHT) was out of normal limits or at the limit $[29,30]$. We included only one eye per participants and we chose the eye with the most severe POAG in case of bilateral optic neuropathy.

\section{Blood sampling}

Blood samples were collected from fasted volunteers for plasma lipids and FAs analysis [31]. Lipids extracted from plasma were stored under inert gas then transmethylated with boron trifloride in methanol [32]. Finally, fatty acid methyl esters were isolated with hexane and analyzed by gas chromatography using a Hewlett Packard Model 5890 (Palo Alto, CA, USA) with a CPSI 
L-88 column $(100 \mathrm{mx} 0,25 \mathrm{~mm}$ i.d., fim thickness $0,20 \mu \mathrm{m}$; Varian, Les Ulis, France) equipped with a flame ionization detector. The carrier gas used was hydrogen. Sample concentration were determined by comparison to commercial and synthetic standards. The analysis focused on 25 FAs reported as a percentage of total FAs using the EZChrom Elite software (Agilent Technologies, Massy, France).

\section{Exclusion criteria}

We excluded secondary and angle-closure glaucoma and all participants with missing data on FAs or glaucomatous status.

\section{Statistical analysis}

Continuous variables were expressed as mean \pm standard deviation (SD) or median (interquartile range) when appropriate and categorical variables as number and percentages $(n, \%)$. Bivariate comparisons were performed with Student test or ANOVA or Kruskal Wallis tests for continuous variables and Chi-squared or Fisher exact tests for categorical variables when appropriate. In the first step of the analysis, associations between individual plasma FAs and POAG were evaluated by a multivariable logistic regression analysis. In the second step of the analysis, in order to identify the FAs patterns (included saturated, monounsaturated and polyunsaturated FAs) associated with the presence of POAG, we used the partial leastsquares (PLS) regression method. Before identifying FAs patterns, all FAs variable were centered and reduced at baseline. We retained the PLS component that was significantly associated with the presence of POAG. Identified PUFA pattern was constructed further to a score by weighting FAs concentration with factor weight values. To interpret the FA pattern, we kept those FAs with absolute values of weights $\geq 0.20$. Individual factor scores were then categorized into tertiles. The lowest tertile of FAs pattern scores was defined as the reference group. Models were adjusted for age and sex, lipid-lowering drugs use and axial length. For all analysis, results were considered significant when $P<0.05$. Analysis was performed using SAS software (version 9.4; SAS institute Inc.; Cary, NC, USA).

\section{Results}

Among the 1153 participants of the Montrachet study, 810 were included in this ancillary analysis with 68 participants with POAG (Fig. 1).

Non-participants were statistically older than participants at the inclusion, $82.59 \pm 3.89$ and $82.11 \pm 3.67$ respectively $(P=0.046)$ (Table 1$)$. Clinical and demographic characteristics of POAG participants and participants without neuropathy are presented in Table 2. POAG participants were older $(P<0.003)$, had a higher axial length $(P<0.006)$ and higher vertical cup disc ratio $(P<0.001)$. The mean percentage of PUFAs in both groups was presented in Table 3. The univariate analysis showed that POAG participants had a significantly lower level of EPA $(P=0.032)$. There was no significant association for others FAs (including DHA) as well as for total omega 3 and omega 6 . The omega 6 / omega 3 ratio was high in both groups, $7.89 \pm 2.15$ and $7.97 \pm 1.56$, respectively $(P=$ $0.775)$.

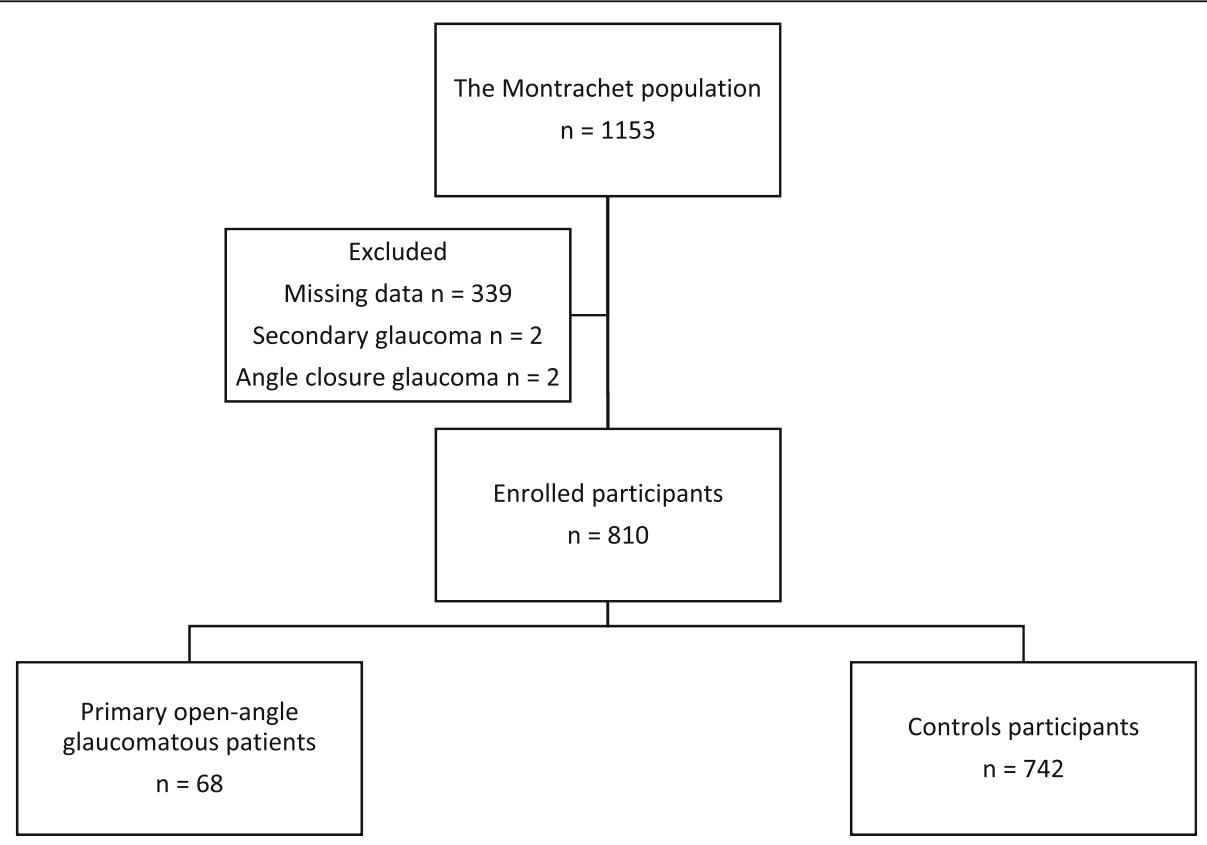

Fig. 1 Flow chart of the study 
Table 1 Baseline characteristics of participants to the Montrachet study ( $n=1153)$, according to their inclusion in the present study

\begin{tabular}{|c|c|c|c|}
\hline Baseline characteristics & $\begin{array}{l}\text { Included } \\
n=810\end{array}$ & $\begin{array}{l}\text { Not } \\
\text { included } \\
n=343\end{array}$ & $P$ \\
\hline Age, years & $82.11 \pm 3.67$ & $82.59 \pm 3.89$ & 0.046 \\
\hline \multicolumn{4}{|l|}{ Sex } \\
\hline Male & $292(36.05)$ & $138(40.23)$ & 0.179 \\
\hline Smoking status, yes, $n=1132$ & $282(35.43)$ & $108(32.14)$ & 0.288 \\
\hline Alcohol consumption, yes, $n=1017$ & $46(6.30)$ & $18(6.27)$ & 0.986 \\
\hline Body mass index & $379(46.79)$ & $175(51.02)$ & 0.189 \\
\hline Diabetic retinopathy, $n=1016$ & $7(0.86)$ & $2(0.58)$ & 1.00 \\
\hline Age-related macular degeneration (AMD) stage, $n=1068$ & & & 0.350 \\
\hline No AMD & $412(54.71)$ & $175(55.56)$ & \\
\hline Early AMD 1 & $235(31.21)$ & $102(32.38)$ & \\
\hline Early AMD 2 & $78(10.36)$ & $22(6.98)$ & \\
\hline Early AMD 3 & $15(1.99)$ & $7(2.22)$ & \\
\hline Late AMD & $13(1.73)$ & $9(2.86)$ & \\
\hline Intraocular pressure, $\mathrm{mmHg}$ & $15.49 \pm 3.32$ & $15.44 \pm 3.64$ & 0.844 \\
\hline Cup/Disc ratio $n=1111$ & $0.36 \pm 0.22$ & $0.38 \pm 0.21$ & 0.179 \\
\hline Axial length, $\mathrm{mm}, n=955$ & $23.44 \pm 1.30$ & $23.46 \pm 1.39$ & 0.845 \\
\hline Antihypertensive treatment, $n=1017$ & $442(60.55)$ & $173(60.28)$ & 0.937 \\
\hline Lipid lowering drug use, $n=1017$ & $311(42.60)$ & $113(39.37)$ & 0.347 \\
\hline Plasma total cholesterol, $\mathrm{mmol} / \mathrm{l}, n=1139$ & $5.80 \pm 0.96$ & $5.78 \pm 0.92$ & 0.649 \\
\hline Low density lipoprotein, mmol// & $3.61 \pm 0.96$ & $3.59 \pm 0.81$ & 0.759 \\
\hline High density lipoprotein, mmol/l & $1.67 \pm 0.40$ & $1.65 \pm 0.41$ & 0.354 \\
\hline Triglycerides, mmol/l & $1.17 \pm 0.50$ & $1.20 \pm 0.55$ & 0.384 \\
\hline
\end{tabular}

$P$ value was calculated between participants and non-participants

The results are displayed as $n(\%)$ for categorical variables and mean \pm standard deviation for continuous variables

After adjustment for age, sex, axial length and lipidlowering drug intakes there was no significant association between EPA and POAG $(P=0.058)$ (Table 4$)$.

A plasma FAs pattern associated with the presence of POAG has been identified. This pattern explained 10.0\% of the total variance in the original set of FAs. The pattern presented high negative weight of gamma-linoleic acid (GLA) and EPA PUFAs and Cis-7 hexadecenoic acid monounsaturated FAs (MUFAs). On the contrary, this pattern presented high positive weight of eicosadienoic acid, docosatetraenoic acid, docosapentaenoic n-6, ALA PUFAs, eicosenoic acid MUFAs and margaric acid and behenic acid saturated FAs (SFA) (Table 5).

The association of FAs pattern scores by tertiles and the presence of POAG is presented in Table 6. We found a positive and significant association between FAs pattern scores and POAG (OR crude T3 vs. T1 $=3.08[95 \%$ CI 1.51-6.27], $P<0.01)$. Similar results were found after controlling for age and sex $\left(\mathrm{OR} \mathrm{T}_{3}\right.$ vs. T1 $=3.01[95 \% \mathrm{CI}$ 1.47-6.14], $P<0.01$ ) and further adjustments for axial length and lipid-lowering drug intakes $\left(\mathrm{OR}_{\mathrm{adj}} \mathrm{T} 3\right.$ vs. $\mathrm{T1}=$ 3.09 [95\% CI 1.29-7.40], $P<0.01$ ).

\section{Discussion}

In this population-based study we compared plasma FAs levels in participants with POAG and in participants without neuropathy by means of two methods: FAs individually and covariance analysis. We did not find any difference regarding plasma FAs level in POAG participants compared to participants without neuropathy after multivariable analysis.

Our results are not in line with previous studies which found an association between the level of plasma and RBCm FAs and glaucoma [19-21, 33]. Ren et al. reported a decrease of EPA, DHA, ALA, and total omega 3 in glaucoma with a linear association with severity of POAG [20]. Yu et al. found a decrease of EPA only in severe NTG [21]. Acar et al. found that DHA level in $\mathrm{RBCm}$ was decreased in POAG patients in the preclinical stage [19]. At the opposite, Yuki did not find any association between NTG and FAs [33]. Contrary to our study, these studies were conducted with univariate statistical analysis and they included a smaller selected population. Moreover our population based study analyzed older age participants with a mean age of 82 years. 
Table 2 Demographics and clinical characteristics between primary open-angle glaucomatous participants and participants without neuropathy in the Montrachet study

\begin{tabular}{|c|c|c|c|c|}
\hline Baseline characteristics & $\begin{array}{l}\text { Total } \\
\mathrm{n}=\mathbf{8 1 0}\end{array}$ & $\begin{array}{l}\text { Participants without } \\
\text { neuropathy } \\
n=742\end{array}$ & $\begin{array}{l}\text { Participants with Primary } \\
\text { open-angle glaucoma } \\
n=68\end{array}$ & $P$ \\
\hline Age, years & $82.11 \pm 3.67$ & $81.99 \pm 3.62$ & $83.36 \pm 4.07$ & 0.003 \\
\hline \multicolumn{5}{|l|}{ Sex } \\
\hline Male & $292(36.05)$ & $266(35.85)$ & $26(38.24)$ & 0.695 \\
\hline Smoking status, yes, $n=96$ & $282(35.43)$ & $257(35.16)$ & $25(38.46)$ & 0.594 \\
\hline Alcohol consumption, yes, $n=730$ & $46(6.30)$ & $44(6.58)$ & $2(3.28)$ & 0.312 \\
\hline Body mass index, $>25 \mathrm{~kg} / \mathrm{m}^{2}$ & $379(46.79)$ & $348(46.90)$ & $31(45.59)$ & 0.836 \\
\hline Diabetes, $n=729$ & $66(9.05)$ & $58(8.68)$ & $8(13.11)$ & 0.248 \\
\hline Diabetic retinopathy & $7(0.86)$ & $7(0.94)$ & $0(0.00)$ & \\
\hline $\begin{array}{l}\text { Age-related maculopathy degeneration (AMD) stage, } n= \\
753\end{array}$ & & & & 0.530 \\
\hline No AMD & $412(54.71)$ & $381(55.14)$ & $31(50.00)$ & \\
\hline Early AMD stage 1 & $235(31.21)$ & $213(30.82)$ & $22(35.48)$ & \\
\hline Early AMD stage 2 & $78(10.36)$ & $71(10.27)$ & $7(11.29)$ & \\
\hline Early AMD stage 3 & $15(1.99)$ & $15(2.17)$ & $0(0.00)$ & \\
\hline Late AMD & $13(1.73)$ & $11(1.59)$ & $2(3.23)$ & \\
\hline Intraocular pressure, $\mathrm{mmHg}$ & $15.49 \pm 3.32$ & $15.46 \pm 3.32$ & $15.81 \pm 3.35$ & 0.407 \\
\hline Cup/Disc Ratio, $n=780$ & $0.36 \pm 0.22$ & $0.32 \pm 0.19$ & $0.74 \pm 0.09$ & $\begin{array}{l}< \\
0.0001\end{array}$ \\
\hline Mean deviation of visual field, $d B, n=783$ & $\begin{array}{l}-11.69 \pm \\
8.12\end{array}$ & NA & $-11.69 \pm 8.12$ & NA \\
\hline Axial length, $\mu \mathrm{m}, n=664$ & $23.44 \pm 1.30$ & $23.39 \pm 1.24$ & $23.88 \pm 1.77$ & 0.006 \\
\hline Antihypertensive treatment, $n=730$ & $442(60.55)$ & $400(59.79)$ & $42(68.85)$ & 0.166 \\
\hline Lipid lowering drug use, $n=730$ & $331(42.60)$ & $283(42.30)$ & $28(45.90)$ & 0.586 \\
\hline Plasma total cholesterol, mmol// & $5.80 \pm 0.96$ & $5.81 \pm 0.97$ & $5.82 \pm 0.75$ & 0.921 \\
\hline Low density lipoprotein, mmol// & $3.61 \pm 0.84$ & $3.60 \pm 0.86$ & $3.65 \pm 0.69$ & 0.650 \\
\hline High density lipoprotein, mmol/l & $1.67 \pm 0.40$ & $1.67 \pm 0.39$ & $1.64 \pm 0.43$ & 0.567 \\
\hline Triglycerides, mmol/l & $1.17 \pm 0.50$ & $1.17 \pm 0.51$ & $1.15 \pm 0.43$ & 0.781 \\
\hline
\end{tabular}

$P$ value was calculated between participants without neuropathy and participants with primary open-angle glaucoma The results are displayed as $n(\%)$ for categorical variables and mean \pm standard deviation for continuous variables

We found a high ratio of omega 6 / omega 3 in the two groups. According to the nutritional recommendations this ratio should be comprised between 2 and 3 in order to reduce the risk of cardiovascular and neurodegenerative diseases [17]. Moreover, according to the nutritional AFSSA recommendation the linoleic acid (LA) / ALA ratio should be around 5 [34]. In this study both groups are 6 times superior to this recommendation [34]. This is in line with our previous findings showing that Montrachet population was in very good health.

We identified a specific plasma FAs pattern significantly associated with POAG. After adjustment for major confounders, individuals in the upper tertile of FAs pattern scores compared with those in the lower tertile were more likely to present POAG. This FAs parttern seems to be associated with POAG in our old population. The analysis of a FAs pattern might be more appropriate to investigate the pathogenesis of glaucoma rather than considering FAs individually.

The involvement of FAs in the pathogenesis of glaucoma could intervene at three different levels. First, FAs have an anti-inflammatory and neuroprotective effect in the retina by preventing the apoptosis of retinal cells and by regulating glia [16]. They are also major components of cell membranes and therefore have a key role in the fluidity and the aggregability of RBC [35, 36]. An imbalance in their composition could lead to decreased ocular blood flow and optic nerve perfusion pressure as it is found in glaucomatous patients [37]. Finally, they are known to be the precursors of prostaglandins, well known for these hypotonizing and anti-inflammatory effects. 
Table 3 Mean percentages of fatty acids between primary open-angle glaucomatous participants and participants without neuropathy

\begin{tabular}{|c|c|c|c|c|c|}
\hline Chemical structure & Common name & Total & $\begin{array}{l}\text { Participants without } \\
\text { neuropathy }\end{array}$ & $\begin{array}{l}\text { Participants with Primary open-angle } \\
\text { glaucoma }\end{array}$ & $P$ \\
\hline \multicolumn{6}{|l|}{ Omega 6} \\
\hline C18:2 n-6 & Linoleic acid (LA) & $25.03 \pm 3.87$ & $25.04 \pm 3.89$ & $24.95 \pm 3.68$ & 0.854 \\
\hline C18:3 n-6 & Gamma linoleic acid (GLA) & $0.45 \pm 0.17$ & $0.46 \pm 0.17$ & $0.43 \pm 0.15$ & 0.225 \\
\hline$C 20: 3 n-6$ & $\begin{array}{l}\text { Dihomo-gamma-linoleic acid } \\
\text { (DGLA) }\end{array}$ & $1.53 \pm 0.32$ & $1.53 \pm 0.32$ & $1.55 \pm 0.31$ & 0.605 \\
\hline C20:4 n-6 & Arachidonic acid (AA) & $7.46 \pm 1.48$ & $7.45 \pm 1.47$ & $7.54 \pm 1.53$ & 0.624 \\
\hline$C 22: 4 n-6$ & Docosatetraenoic Acid (DTA) & $0.26 \pm 0.07$ & $0.25 \pm 0.07$ & $0.27 \pm 0.10$ & 0.164 \\
\hline$C 22: 5 n-6$ & Docosapentaenoic n-6 (DPA) & $0.17 \pm 0.05$ & $0.17 \pm 0.05$ & $0.18 \pm 0.06$ & 0.148 \\
\hline \multicolumn{6}{|l|}{ Omega 3} \\
\hline C18:3 n-3 & Alpha linoleic acid (ALA) & $0.63 \pm 0.21$ & $0.63 \pm 0.21$ & $0.68 \pm 0.25$ & 0.065 \\
\hline C20:5 n-3 & Eicosapentaenoic acid (EPA) & $1.29 \pm 0.62$ & $1.30 \pm 0.64$ & $1.13 \pm 0.34$ & 0.032 \\
\hline$C 22: 5 n-3$ & Docosapentaenoic n-3 (DPA) & $0.59 \pm 0.13$ & $0.59 \pm 0.13$ & $0.59 \pm 0.14$ & 0.957 \\
\hline$C 22: 6 n-3$ & Docosahexaenoic acid (DHA) & $2.22 \pm 0.65$ & $2.23 \pm 0.66$ & $2.15 \pm 0.51$ & 0.366 \\
\hline \multicolumn{6}{|l|}{ Sum } \\
\hline Omega 6 & & $35.15 \pm 4.03$ & $35.14 \pm 4.08$ & $35.22 \pm 3.42$ & 0.869 \\
\hline Omega 3 & & $4.74 \pm 1.30$ & $4.76 \pm 1.33$ & $4.56 \pm 0.87$ & 0.243 \\
\hline $\begin{array}{l}\text { Polyunsaturated } \\
\text { fatty acids }\end{array}$ & & $40.36 \pm 4.18$ & $40.37 \pm 4.23$ & $40.31 \pm 3.63$ & 0.916 \\
\hline \multicolumn{6}{|l|}{ Ratios } \\
\hline LA/ALA & & $43.43 \pm 14.67$ & $43.73 \pm 14.92$ & $40.12 \pm 11.14$ & 0.052 \\
\hline $\begin{array}{l}\text { Sum Omega } 6 \text { / } \\
\text { Omega } 3\end{array}$ & & $7.90 \pm 2.11$ & $7.89 \pm 2.15$ & $7.97 \pm 1.56$ & 0.775 \\
\hline
\end{tabular}

$P$ value was calculated between controls and primary open-angle glaucomatous participants

The results are expressed as mean ( \pm standard deviation) of total fatty acids

In that perspective, previous studies have investigated if diet modification could have a protective effect. Nguyen demonstrated in rats that rich diet of omega 3 FAs causes better retinal ganglion cell function, and similarly decreases IOP. Similarly, deficiency in omega 3 FAs causes dysfunction [38-40]. In humans, no strong association have been established between PUFAs intakes and glaucoma. Renard suggested in a recent observational study on a French glaucomatous population

Table 4 Associations of plasma polyunsaturated fatty acids with primary open-angle glaucoma

\begin{tabular}{lll}
\hline & \multicolumn{2}{l}{ Primary open-angle glaucoma } \\
\cline { 2 - 3 } & OR $(\mathbf{9 5 \%}, \mathbf{C l})$ & $\boldsymbol{P}$ \\
\hline Eicosadienoic acid & $2.38(0.91-6.22)$ & 0.078 \\
Alpha linoleic acid & $2.73(0.77-9.65)$ & 0.119 \\
Eicosapentaenoic acid & $0.56(0.31-1.02)$ & 0.058 \\
Docosahexaenoic acid & $0.82(0.53-1.28)$ & 0.378
\end{tabular}

After adjustments for age, sex, axial length and lipid-lowering drug use OR Odd Ratio, Cl Confidence Interval

Two hundred twelve observations were not taken into account due to missing values from axial length and lipid-lowering drug use that omega 3 fatty acids intake have a protective effect against POAG [41]. A recent observational populationbased study suggest that an increased DHA and EPA and global omega 3 intake decrease the risk of glaucoma only if global PUFAs level intake is controlled [42]. A randomized controlled trial conducted by Garcia Medina did not find any improvement in glaucoma with antioxidants (with and without omega 3) intake [43]. Moreover, Kang found that a globally high omega 3 / omega 6 ratio increases the risk of glaucoma [44].

As no strong evidence of specifics FAs implication was demonstrated in our study, the benefit of supplementation in some FAs remains debated.

We acknowledge several limitations to this study. First, participants of Montrachet study are Caucasian, voluntary, elderly and from an urban population. These volunteers follow a healthy lifestyle. We could not extrapolate our results to another group. Second, we included uneven number of participants in the two groups because there were not many subjects diagnosed with glaucoma and therefore limits the interpretation of the results. Furthermore, the low number of participants with primary open-angle glaucoma could have reduced the 
Table 5 Weight values of 25 plasma fatty acids obtained by the partial least-squares discriminant analysis in the Montrachet study

\begin{tabular}{|c|c|c|}
\hline \multicolumn{2}{|c|}{ Fatty acids } & Component \\
\hline \multicolumn{3}{|c|}{ Saturated fatty acids } \\
\hline $\mathrm{C} 12: 0$ & Lauric acid & -0.01 \\
\hline C14:0 & Myristic acid & -0.10 \\
\hline C15:0 & Pentadecanoic acid & 0.15 \\
\hline C16:0 & Palmitic acid & 0.07 \\
\hline C17:0 & Margaric acid & 0.22 \\
\hline C18:0 & Stearic acid & 0.07 \\
\hline$C 20: 0$ & Arachidic acid & 0.16 \\
\hline $\mathrm{C} 22: 0$ & Behenic acid & 0.28 \\
\hline \multicolumn{3}{|c|}{ Monounsaturated fatty acids } \\
\hline C16:1 n-7 & Palmitoleic acid & -0.12 \\
\hline C16:1 n-9 & Cis-7 hexadecenoic acid & -0.22 \\
\hline C18:1 n-7 & Vaccenic acid & 0.06 \\
\hline C18:1 n-9 & Oleic acid & -0.03 \\
\hline C20:1 n-9 & Eicosenoic acid & 0.35 \\
\hline C24:1 n-9 & Nervonic acid & 0.08 \\
\hline \multicolumn{3}{|c|}{ Polyunsaturated fatty acids } \\
\hline \multicolumn{3}{|l|}{ Omega 6} \\
\hline C18:2 n-6 & Linoleic acid (LA) & -0.04 \\
\hline C18:3 n-6 & Gamma linoleic acid (GLA) & -0.25 \\
\hline$C 20: 2 n-6$ & Eicosadienoic acid & 0.60 \\
\hline$C 20: 3 n-6$ & Dihomo-gamma-linoleic acid (DGLA) & 0.11 \\
\hline C20:4 n-6 & Arachidonic acid (AA) & 0.10 \\
\hline$C 22: 4 n-6$ & Docosatetraenoic acid (DTA) & 0.29 \\
\hline$C 22: 5 n-6$ & Docosapentaenoic acid n-6 (DPA) & 0.30 \\
\hline \multicolumn{3}{|l|}{ Omega 3} \\
\hline C18:3n-3 & Alpha linoleic acid (ALA) & 0.38 \\
\hline$C 20: 5 n-3$ & Eicosapentaenoic acid (EPA) & -0.44 \\
\hline$C 22: 5 n-3$ & Docosapentaenoic acid n-3 (DPA) & 0.01 \\
\hline$C 22: 6 n-3$ & Docosahexaenoic acid (DHA) & -0.19 \\
\hline
\end{tabular}

The fatty acids pattern obtained by Partial Least Squares Discriminant Analysis explained $10.0 \%$ of the variance in all FAs and $2.2 \%$ of the variance in response variable

Values in bold indicate interpretable FAs with absolute values of weights $\geq 0.20$

statistical power of the analysis. Third, our study did not include any analysis of the food intake of the participants. Fourth, we used only plasma analysis of FAs. This could lead to bias of measure, as it only reflects recent dietary intake compared to RBCm FAs analysis [45, 46].

In conclusion, there is no significant difference regarding plasma FAs level in multivariate analysis when FAs are analyzed isolated. The global study of FAs highlighted a specific FAs pattern associated with POAG. The clinical relevance of this pattern warrants further studies.
Table 6 Multivariable associations of fatty acids pattern scores and the presence of primary open-angle glaucoma in the Montrachet study

\begin{tabular}{lllll}
\hline & & \multicolumn{2}{l}{ Tertiles of fatty acids pattern scores } & \\
\cline { 3 - 4 } & T1 & T2 & T3 & \\
& OR (95\% Cl) & OR $(\mathbf{9 5 \% ~ C l )}$ & OR $(\mathbf{9 5 \%}$ Cl) & $P$ \\
\hline Crude & 1.00 (Ref.) & $2.40(1.16-4.96)$ & $3.08(1.51-6.27)$ & 0.002 \\
M1 & 1.00 (Ref.) & $2.46(1.18-5.10)$ & $3.01(1.47-6.14)$ & 0.003 \\
M2 & 1.00 (Ref.) & $2.52(1.04-6.13)$ & $3.09(1.29-7.40)$ & 0.013 \\
\hline
\end{tabular}

Ref Reference, OR Odds ratio, $\mathrm{Cl}$ Confidence interval, 11 First tertile, $\mathrm{T} 2$ Second tertile, $\mathrm{T} 3=$ third tertile

M1: age and sex-adjusted model

M2: M1 with further adjustment for axial length and lipid-lowering drug use Two hundred twelve observations were deleted due to missing values from axial length and lipid-lowering drug use

\section{Acknowledgements}

We thank Prof. Binquet Christine and the CIC-EC for their support.

\section{Authors' contributions}

AC, analysis, interpretation of data, have drafted the work or substantively revised it; $L A$, analysis, interpretation of data, have drafted the work or substantively revised it; $\mathrm{AS}$, analysis and interpretation of data; $\mathrm{PHG}$, revision of the draft; FB, revision of the draft; NA, conception and design of the work; CCG, conception and revision of the work. Each authors have approved the submitted version and have agreed both to be personally accountable for the author's own contributions and to ensure that questions related to the accuracy or integrity of any part of the work, even ones in which the author was not personally involved, are appropriately investigated, resolved, and the resolution documented in the literature.

\section{Funding}

Supported by an interregional grant (Programme Hospitalier de Recherche (linique) and the Regional Council of Burgundy; by INRA, CNRS, Université de Bourgogne, Regional Council of Burgundy France (PARI Agrale 1), FEDER (European Funding for Regional Economic Development); and a French Government grant managed by the French National Research Agency (ANR) under the "Investissements d'Avenir" program, ANR-11-LABX-0021-01-LipSTIC Labex.

\section{Availability of data and materials}

The data that support the findings of this study are available from the $3 \mathrm{C}$ Committee but restrictions apply to the availability of these data, which were used under license for the current study, and so are not publicly available. Data are however available from the authors upon reasonable request and with permission of 3C Committee (E3C.U708@inserm.fr or louis.arnould@chudijon.fr).

\section{Declarations}

\section{Ethics approval and consent to participate}

The study has been approved by the Ethical Committee of the 3 Cities Study and registered as 2009-A00448-49. Written informed consent was obtained from the participants or from legal guardians of the participants if they are blind and the study followed the tenets of the Declaration of Helsinki.

\section{Consent for publication}

Not applicable.

\section{Competing interests}

The authors declare that they have no non-financial competing interests. Disclosure: AC, None; LA, None; AS, None; PHG, None; FB, Novartis (C), Thea $(C)$; NA, None; CCG, Allergan (C), Bayer (C), Horus (C), Novartis (C), Roche (C), Théa (C). 


\section{Author details}

'Department of Ophthalmology, University Hospital, 14 rue Paul Gaffarel, 21079 Dijon CEDEX, France. ${ }^{2}$ INSERM \& Dijon University Hospital, CIC1432, Clinical Epidemiology Unit, Dijon, France. ${ }^{3}$ Centre des Sciences du Goût et de l'Alimentation, AgroSup Dijon, CNRS, INRAE, Université de Bourgogne Franche-Comté, F-21000 Dijon, France. ${ }^{4}$ EA7460, PEC2, Cerebral and Cardiovascular epidemiology and physiopathology, Dijon, France.

\section{Received: 16 February 2021 Accepted: 11 March 2021}

\section{Published online: 23 March 2021}

\section{References}

1. Flaxman SR, Bourne RRA, Resnikoff S, Ackland P, Braithwaite T, Cicinelli MV et al. Global causes of blindness and distance vision impairment 1990-2020: a systematic review and meta-analysis. Lancet Glob Health. 2017:5(12): e1221-34. https://doi.org/10.1016/S2214-109X(17)30393-5.

2. Tham Y-C, Li X, Wong TY, Quigley HA, Aung T, Cheng C-Y. Global prevalence of glaucoma and projections of glaucoma burden through 2040: a systematic review and meta-analysis. Ophthalmol. 2014;121(11):2081-90. https://doi.org/10.1016/j.ophtha.2014.05.013.

3. The advanced glaucoma intervention study, 6 : effect of cataract on visual field and visual acuity. The AGIS investigators. Arch Ophthalmol. 2000;118: 1639-52.

4. Jonas JB, Aung T, Bourne RR, Bron AM, Ritch R, Panda-Jonas S. Glaucoma. Lancet. 2017;390(10108):2183-93. https://doi.org/10.1016/S0140-6736(17)314 69-1.

5. Sommer A, Tielsch JM, Katz J, Quigley HA, Gottsch JD, Javitt J, et al. Relationship between intraocular pressure and primary open angle glaucoma among white and black Americans. The Baltimore eye survey. Arch Ophthalmol. 1991;109(8):1090-5. https://doi.org/10.1001/archopht.1 991.01080080050026

6. Flammer J, Orgul S, Costa VP, et al. The impact of ocular blood flow in glaucoma. Prog Retin Eye Res. 2002;21(4):359-93. https://doi.org/10.1016/ S1350-9462(02)00008-3

7. Flammer J, Pache $M$, Resink T. Vasospasm, its role in the pathogenesis of diseases with particular reference to the eye. Prog Retin Eye Res. 2001;20(3): 319-49. https://doi.org/10.1016/S1350-9462(00)00028-8.

8. Lichter PR, Musch DC, Gillespie BW, Guire KE, Janz NK, Wren PA, et al. Interim clinical outcomes in the collaborative initial glaucoma treatment study comparing initial treatment randomized to medications or surgery Ophthalmology. 2001;108(11):1943-53. https://doi.org/10.1016/S0161-642 0(01)00873-9.

9. Heijl A, Leske MC, Bengtsson B, Hyman L, Bengtsson B, Hussein M. Reduction of intraocular pressure and glaucoma progression: results from the early manifest glaucoma trial. Arch Ophthalmol. 2002;120(10):1268-79. https://doi.org/10.1001/archopht.120.10.1268.

10. Tezel G. Oxidative stress in glaucomatous neurodegeneration: mechanisms and consequences. Prog Retin Eye Res. 2006;25(5):490-513. https://doi.org/1 0.1016/j.preteyeres.2006.07.003.

11. Vohra R, Tsai JC, Kolko M. The role of inflammation in the pathogenesis of glaucoma. Surv Ophthalmol. 2013;58(4):311-20. https://doi.org/10.1016/j. survophthal.2012.08.010.

12. Benatti $P$, Peluso G, Nicolai $R$, Calvani M. Polyunsaturated fatty acids: biochemical, nutritional and epigenetic properties. J Am Coll Nutr. 2004; 23(4):281-302. https://doi.org/10.1080/07315724.2004.10719371.

13. Kao Y-C, Ho P-C, Tu Y-K, Jou I-M, Tsai K-J. Lipids and Alzheimer's disease. Int J Mol Sci. 2020;21(4). https://doi.org/10.3390/ijms21041505.

14. Lynch AM, Loane DJ, Minogue AM, Clarke RM, Kilroy D, Nally RE, et al. Eicosapentaenoic acid confers neuroprotection in the amyloid-beta challenged aged hippocampus. Neurobiol Aging. 2007;28(6):845-55. https:// doi.org/10.1016/j.neurobiolaging.2006.04.006.

15. von Schacky C. Omega-3 fatty acids and cardiovascular disease. Curr Opin Clin Nutr Metab Care. 2004;7(2):131-6. https://doi.org/10.1097/00075197-2 00403000-00005.

16. German OL, Insua MF, Gentili C, Rotstein NP, Politi LE. Docosahexaenoic acid prevents apoptosis of retina photoreceptors by activating the ERK/MAPK pathway. J Neurochem. 2006;98(5):1507-20. https://doi.org/10.1111/j.14 71-4159.2006.04061.x.

17. SanGiovanni JP, Chew EY. The role of omega-3 long-chain polyunsaturated fatty acids in health and disease of the retina. Prog Retin Eye Res. 2005; 24(1):87-138. https://doi.org/10.1016/j.preteyeres.2004.06.002.
18. Eynard AR, Repossi G. Role of $\omega 3$ polyunsaturated fatty acids in diabetic retinopathy: a morphological and metabolically cross talk among blood retina barriers damage, autoimmunity and chronic inflammation. Lipids Health Dis. 2019:18(1):114. https://doi.org/10.1186/s12944-019-1049-9.

19. Acar N, Berdeaux O, Juaneda P, Grégoire S, Cabaret S, Joffre C, et al. Red blood cell plasmalogens and docosahexaenoic acid are independently reduced in primary open-angle glaucoma. Exp Eye Res. 2009;89(6):840-53. https://doi.org/10.1016/j.exer.2009.07.008.

20. Ren H, Magulike N, Ghebremeskel K, Crawford M. Primary open-angle glaucoma patients have reduced levels of blood docosahexaenoic and eicosapentaenoic acids. Prostaglandins Leukot Essent Fatty Acids. 2006;74(3): 157-63. https://doi.org/10.1016/j.plefa.2005.11.007.

21. Yu M, Chen B, Gong B, Shuai P, Wu Z-Z, Lin W. Association of $n 3$ and $n 6$ polyunsaturated fatty acids in red blood cell membrane and plasma with severity of normal tension glaucoma. Int J Ophthalmol. 2015;8(3):476-83. https://doi.org/10.3980/j.issn.2222-3959.2015.03.08.

22. Creuzot-Garcher C, Binquet C, Daniel S, Bretillon L, Acar N, de Lazzer A, et al. The Montrachet study: study design, methodology and analysis of visual acuity and refractive errors in an elderly population. Acta Ophthalmol. 2016; 94(2):e90-7. https://doi.org/10.1111/aos.12842.

23. Group CS. Vascular factors and risk of dementia: design of the Three-City study and baseline characteristics of the study population. Neuroepidemiology. 2003;22:316-25.

24. von Elm E, Altman DG, Egger M, Pocock SJ, Gøtzsche PC, Vandenbroucke $J P$. The strengthening the reporting of observational studies in epidemiology (STROBE) statement: guidelines for reporting observational studies. J Clin Epidemiol. 2008;61(4):344-9. https://doi.org/10.1016/j.jclinepi.2 007.11.008.

25. Groves T. Enhancing the quality and transparency of health research. BMJ. 2008;337(jul08 1):a718. https://doi.org/10.1136/bmj.a718.

26. Foster PJ, Buhrmann R, Quigley HA, Johnson GJ. The definition and classification of glaucoma in prevalence surveys. Br J Ophthalmol. 2002; 86(2):238-42. https://doi.org/10.1136/bjo.86.2.238.

27. Blanc J, Seydou A, Ben Ghezala I, Deschasse C, Meillon C, Bron AM, et al. Vitreomacular Interface abnormalities and glaucoma in an elderly population (the MONTRACHET study). Invest Ophthalmol Vis Sci. 2019;60(6): 1996-2002. https://doi.org/10.1167/iovs.18-26510.

28. Hodapp E, Parrish R, Anderson DR. Clinical decisions in glaucoma; 1993.

29. Asman P, Heijl A. Glaucoma Hemifield test. Automated visual field evaluation. Arch Ophthalmol. 1992;110(6):812-9. https://doi.org/10.1001/a rchopht.1992.01080180084033

30. Öhnell H, Bengtsson B, Heijl A. Making a correct diagnosis of glaucoma: data from the EMGT. J Glaucoma. 2019;28(10):859-64. https://doi.org/10.1 097/IJG.0000000000001342

31. Moilanen T, Nikkari T. The effect of storage on the fatty acid composition of human serum. Clin Chim Acta. 1981;114(1):111-6. https://doi.org/10.1016/ 0009-8981(81)90235-7.

32. Morrison WR, Smith LM. Preparation of fatty acid methyl esters and dimethylacetals from lipids with boron fluoride-methanol. J Lipid Res. 1964; 5(4):600-8. https://doi.org/10.1016/S0022-2275(20)40190-7.

33. Yuki K, Kimura I, Tsubota K. Serum free fatty acids levels not associated with normal tension glaucoma. Clin Ophthalmol. 2010;4:91-4. https://doi.org/1 0.2147/opth.s9418.

34. Agence nationale de sécurité sanitaire de l'alimentation, de l'environnement et du travail. Acide gras de la famille des Oméga 3 et système cardiovasculaire : intérêt nutritionnel et allégations. Available on: https:// www.anses.fr/fr/content/acide-gras-de-la-famille-des-om\%C3\%A9ga-3-etsyst\%C3\%A8me-cardiovasculaire\%C2\%A0-int\%C3\%A9r\%C3\%AAtnutritionnel-et-0. Accessed (9 Aug 2020), 2003.

35. Eschen $\mathrm{O}$, Christensen JH, De Caterina R, Schmidt EB. Soluble adhesion molecules in healthy subjects: a dose-response study using n-3 fatty acids. Nutr Metab Cardiovasc Dis. 2004;14(4):180-5. https://doi.org/10.1016/S093 9-4753(04)80002-4

36. Popp-Snijders C, Schouten JA, van der Meer J, van der Veen EA. Fatty fishinduced changes in membrane lipid composition and viscosity of human erythrocyte suspensions. Scand J Clin Lab Invest. 1986;46(3):253-8. https:// doi.org/10.3109/00365518609083667.

37. Hamard $\mathrm{P}$, Hamard $\mathrm{H}$, Dufaux J. Blood flow rate in the microvasculature of the optic nerve head in primary open angle glaucoma. A new approach. Surv Ophthalmol. 1994:38 Suppl:S87-93 discussion 594 
38. Nguyen CTO, Vingrys AJ, Bui BV. Dietary omega-3 fatty acids and ganglion cell function. Invest Ophthalmol Vis Sci. 2008;49(8):3586-94. https://doi.org/1 $0.1167 /$ iovs.08-1735.

39. Nguyen CTO, Bui BV, Sinclair AJ, Vingrys AJ. Dietary omega 3 fatty acids decrease intraocular pressure with age by increasing aqueous outflow. Invest Ophthalmol Vis Sci. 2007:48(2):756-62. https://doi.org/10.1167/iovs.06-0585.

40. Nguyen CTO, Vingrys AJ, Bui BV. Dietary $\omega-3$ deficiency and IOP insult are additive risk factors for ganglion cell dysfunction. J Glaucoma. 2013;22(4): 269-77. https://doi.org/10.1097/JJG.0b013e318237cac7.

41. Renard J-P, Rouland J-F, Bron A, Sellem E, Nordmann JP, Baudouin C, et al. Nutritional, lifestyle and environmental factors in ocular hypertension and primary open-angle glaucoma: an exploratory case-control study. Acta Ophthalmol. 2013; 91(6):505-13. https:/doi.org/10.1111/.j.1755-3768.2011.02356.x.

42. Wang YE, Tseng VL, Yu F, Caprioli J, Coleman AL. Association of Dietary Fatty Acid Intake with glaucoma in the United States. JAMA Ophthalmol. 2018;136(2):141-7. https://doi.org/10.1001/jamaophthalmol.2017.5702.

43. Garcia-Medina JJ, Pinazo-Duran MD, Garcia-Medina M, Zanon-Moreno V Pons-Vazquez S. A 5-year follow-up of antioxidant supplementation in type 2 diabetic retinopathy. Eur J Ophthalmol. 2011;21(5):637-43. https://doi. org/10.5301/EJO.2010.6212

44. Kang JH, Pasquale LR, Willett WC, Rosner BA, Egan KM, Faberowski N, et al. Dietary fat consumption and primary open-angle glaucoma. Am J Clin Nutr. 2004;79(5):755-64. https://doi.org/10.1093/ajcn/79.5.755.

45. Arab L. Biomarkers of fat and fatty acid intake. J Nutr. 2003;133(3):925S-32S. https://doi.org/10.1093/jn/133.3.925S.

46. Acar N, Berdeaux O, Grégoire S, Cabaret S, Martine L, Gain P, et al. Lipid composition of the human eye: are red blood cells a good mirror of retinal and optic nerve fatty acids? PLoS One. 2012;7(4):e35102. https://doi.org/1 0.1371/journal.pone.0035102.

\section{Publisher's Note}

Springer Nature remains neutral with regard to jurisdictional claims in published maps and institutional affiliations.

Ready to submit your research? Choose BMC and benefit from:

- fast, convenient online submission

- thorough peer review by experienced researchers in your field

- rapid publication on acceptance

- support for research data, including large and complex data types

- gold Open Access which fosters wider collaboration and increased citations

- maximum visibility for your research: over $100 \mathrm{M}$ website views per year

At BMC, research is always in progress.

Learn more biomedcentral.com/submissions 